Ann. Zootech., I977, 27 (2), I69-I74.

\title{
L'alimentation azotée du caneton de Barbarie : Possibilités de réduction du taux protidique de l'aliment au cours de la période de finition
}

\author{
B. LECLERCQ et H. de CARVILLE \\ Station de Recherches avicoles, \\ Centre de Recherches de Tours, I.N.R.A., \\ Nonzilly 37380 Monnaie (France)
}

\begin{abstract}
Résumé
Deux essais sont entrepris afin de déterminer l'influence du taux azoté des régimes sur la croissance du caneton de Barbarie mâle entre les âges de 6 et Io semaines. On constate une incidence du niveau d'ingestion d'aliment, lié en grande partie à la température ambiante, sur l'estimation du besoin exprimé en pourcentage du régime. L'expression en quantité totale de protéines nécessaire pour une période donnée est plus satisfaisante et permet d'adopter des caractéristiques de régimes différentes selon les conditions d'élevage, en particulier les saisons. Nos résultats permettent d'estimer à $800 \mathrm{~g}$ la quantité totale de protéines nécessaire entre les âges de 6 et ro semaines.
\end{abstract}

\section{Introduction}

Au cours d'une étude antérieure (LECLERCQ et de CARvILLE, I976) nous avons étudié l'influence du taux protidique de l'aliment sur la croissance du caneton mâle entre les âges de 4 et I 2 semaines. Cette étude constituait une première approche d'un sujet jusqu'alors inexploré. Nous avons procédé à une investigation trop large pour être précise. I'une part la période étudiée était trop longue pour permettre de déterminer correctement l'évolution du besoin protéique en fonction de l'âge. D'autre part les régimes, constitués de maîs et de tourteau de soja, présentaient un même rapport acides aminés soufrés/ protéines totales, ce qui ne correspond pas aux conditions pratiques de formulation. Nous avons donc entrepris deux essais destinés à compléter l'étude citée précédemment en nous intéressant à la période s'étendant entre les âges de 6 et ro semaines (période de finition). J) plus les régimes comparés lors d'un même essai présentaient tous la même concentration en acides aminés soufrés totaux pour tenir compte des besoins établis par ailleurs (LECLERCQ et de CARVII,E, I977). 


\section{Matériel et méthodes}

Les conditions d'élevage sont celles décrites antérieurement (LECLERCQ et de CARVILLE, I978). En outre les canetons sont vaccinés à l'âge de 28 jours contre la maladie de Derzsy (rappel Palmivax).

\section{Essai no $I$}

On distribue 4 régimes dont les deux extrêmes sont les deux régimes de base présentés dans le tableau I. Les deux intermédiaires sont obtenus en mélangeant des régimes de base selon les proportions $\mathrm{I} / 3-2 / 3$ ou $2 / 3-\mathrm{I} / 3$. Les taux exacts de matières azotées sont de Io,4-II,7-I2,9 et I $4,2 \mathrm{p}$. cent. Chaque régime est distribué à 3 répétitions de 8 canetons. Au cours de cet essai la température moyenne a été de $22{ }^{\circ} \mathrm{C}$ (moyenne des maxima et minima journaliers).

\section{TABLEAU I}

Composition des régimes de base

Percentage composition of basal diets

(p. cent)

\begin{tabular}{|c|c|c|c|c|}
\hline \multirow{3}{*}{ Tö̊ $\left(\pi T_{\text {aino }}\right.$} & \multicolumn{2}{|c|}{$\begin{array}{l}\text { Esssai } \mathrm{n}^{0} \mathrm{I} \\
(\text { Trial } I)\end{array}$} & \multicolumn{2}{|c|}{$\begin{array}{l}\text { Essai } \mathfrak{n}^{0}{ }^{2} \\
(\text { Trial } 2)^{2}\end{array}$} \\
\hline & $\mathrm{I}$ & 2 & I & 2 \\
\hline & 87,0 & 79,0 & 85,0 & $7^{6,4}$ \\
\hline Tourteau de soja (Soybean meal)..... & 5,0 & 15,0 & 6,0 & 17,0 \\
\hline Cellulose . . . . . . . . . . . & 2,0 & & 2,2 & \\
\hline Liant (Binding agent) . . . . . . . & 2,0 & 2,0 & 2,0 & 2,0 \\
\hline Phosphate bicalcique (Di-calcium phosphate) & $\mathrm{r}, 2$ & $\mathrm{I}, 2$ & $I, 5$ & $\mathrm{I}, 5$ \\
\hline Carbonate de calcium (Calcium carbonate). & 1,8 & 1,8 & 2,0 & 2,0 \\
\hline Sel (Salt) . . . . . . . . & 0,4 & 0,4 & 0,5 & 0,5 \\
\hline Oligo-minéraux (Minerals) $\left({ }^{*}\right), \ldots$ & $0, \mathrm{r}$ & $0, \mathrm{I}$ & $0, I$ & $0, \mathrm{I}$ \\
\hline Mélange vitaminique (Vitamins) $\left.{ }^{*}\right)$. . . & 0,5 & 0,5 & 0,5 & 0,5 \\
\hline $\begin{array}{l}\text { DL méthionine } \\
\text { Valeur énergétique calculée (MJ/kg) iCalculated }\end{array}$ & 0,157 & 0,042 & 0,2 & 0,07 \\
\hline $\begin{array}{l}\text { Energy level) } \\
\text { Taux protidique mesuré }(p . \text { cent)) }(\dot{M e a s u r e d}\end{array}$ & $\mathrm{I} 2,52$ & $\mathrm{I} 2,46$ & $\mathrm{I} 2,35$ & I 2,34 \\
\hline 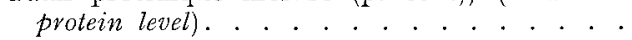 & 10,4 & $\mathrm{I}_{4}, 2$ & $\mathrm{I} 2,2$ & 15,3 \\
\hline $\begin{array}{l}\text { Teneur en lysine ( } \mathrm{p} \text {. cent) (Iysine content). } \\
\text { Teneur en acides aminés soufrés }(\mathrm{p} \text {. cent) (Total }\end{array}$ & $0,3^{8}$ & 0,67 & 0,47 & 0,75 \\
\hline sulphur amino acids) . . . . . . . . . . & 0,57 & 0,57 & 0,62 & 0,62 \\
\hline
\end{tabular}

(*) Voir l,eclferco et de Carville, I977. See Leclerco and de Carvilie, i977.)

\section{Essai $n^{\circ} 2$}

Cet essai est identique au précédent si ce n'est que les régimes de base sont un peu plus riches en matières azotées. Après dosage les teneurs sont de : I2,2 $\mathrm{I}_{3,2}$ - I 4,3 et $\mathrm{I}_{5,3} \mathrm{p}$. cent. Chaque régime est distribué à 3 répétitions de 8 canetons. La température moyenne était de $15,5{ }^{\circ} \mathrm{C}$. 
Tous les canetons sont identifiés par une bague et pesés individuellement après un jeûne total (aliment et eau ) de $16 \mathrm{~h}$. Les comparaisons entre moyennes sont effectuées par le test de NEWMAN et KEULS au seuil de signification de 0,05.

\section{Résultats}

\section{Essai $n^{\circ} I$}

Les résultats de cet essai font l'objet du tableau 2. Les deux régimes les plus pauvres ralentissent la vitesse de croissance. Les deux régimes les plus riches permettent des croissances identiques mais inférieures aux performances moyennes observées habituellement avec ce type de canard. La consommation d'aliment n'est réduite que pour le lot recevant le moins de protéines.

\section{TABLEAU 2}

- Croissance et consommation d'aliment de canetons mâles recevant des régimes à taux protidiques differents entre les âges de 6 et Io semaines (Essai $n^{\circ} I$ )

Growth rate and feed consumption of male muscovy ducklings fed different protein levels from 6 to Io weeks of age (Trial $\left.n^{\circ} x\right)$

Taux protidique mesuré (p. cent) (Actual protein level)

Poids vif à l'âge de 6 semaines (g) (Live weight at 6 weeks) . . . . . . . . .

Poids vif à l'âge de Io semaines (g) (Live weight at Io weehs). . . . . . . . .

Gain de poids vif (g) (Body weight gain).

Consommation d'aliment (g) (Feed consumpion). . . . . . . . . . . . .

Indice de consommation (Fecd to gain ratio) . . . . . . . . . . . . . .

\begin{tabular}{|c|c|c|c|c|}
\hline I 0,4 & $\mathrm{I} I, 7$ & 12,9 & 14,2 & $\begin{array}{c}\text { Test de } \\
\text { linéarité } \\
\text { Linearity } \\
\text { test }\end{array}$ \\
\hline I 949 & $197 \mathrm{I}$ & I 965 & I $97^{\circ}$ & \\
\hline $254^{\circ} a$ & 295 I $b$ & $3162 c$ & 35700 & $6,06\left(^{* *}\right)$ \\
\hline 59 × $a$ & $980 b$ & I $197^{\circ}$ & I $200 \mathrm{c}$ & I 2, OO $(* *)$ \\
\hline $3678 a$ & $4300 b$ & $4555 b$ & $43^{8} 3 b$ & \\
\hline $6,73 a$ & $4,60 b$ & $3,94 b$ & $3,73 \mathrm{~b}$ & \\
\hline
\end{tabular}

(**) Significatif au seuil de I p. cent. (Significant at the threshold of $I$ p. cent.)

Les résultats de cet essai sont présentés dans le tableau 3. Ici encore les deux régimes les plus pauvres en protéines ralentissent la croissance par rapport aux deux autres régimes qui ne diffèrent pas entre enx. Cette fois les vitesses de croissance des meilleurs lots sont normales. 
TABLEAU 3

Croissance et consommation d'aliment de canetons males recevant des régimes $\grave{a}$ taux protidiques differents entre les âges de 6 et Io semaines (Essai $\left.n^{\circ} 2\right)$

Growth rate and feed consumption of male muscovy ducklings fed different protein levels from 6 to ro weeks of age (Trial $n^{\circ} 2$ )

\begin{tabular}{|c|c|c|c|c|c|}
\hline $\begin{array}{l}\text { Taux protidique mesuré (p. cent) (Actual } \\
\text { protein level). . . . . . . }\end{array}$ & $\mathrm{I} 2,2$ & 13,2 & 14,3 & I 5,3 & $\begin{array}{l}\text { Test de } \\
\text { linéarité } \\
\text { Linearity } \\
\quad \text { test }\end{array}$ \\
\hline $\begin{array}{l}\text { Poids vif à l'âge de } 6 \text { semaines (g) (Live } \\
\text { weight at } 6 \text { weeks) }\end{array}$ & 2024 & 2037 & 2073 & 2056 & \\
\hline 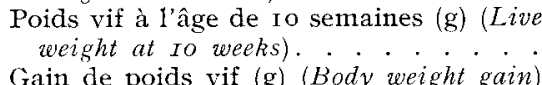 & $\begin{array}{r}3000 a \\
076 a\end{array}$ & $\begin{array}{lll}3 & \text { I } 89 & b \\
\text { I } & \text { I } 52 & b\end{array}$ & $\begin{array}{l}3379 c \\
\mathrm{r} 306 c\end{array}$ & $\begin{array}{l}347^{6} c \\
\text { I } 420 c\end{array}$ & $\begin{array}{l}0,96 \\
0,27\end{array}$ \\
\hline 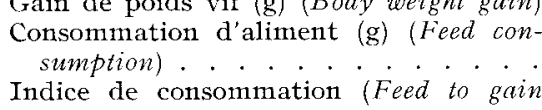 & $4938 a$ & $5 \mathrm{IO} 3 b$ & $5368 c$ & $\begin{array}{l}\text { I } 420 \mathrm{C} \\
5450 \mathrm{C}\end{array}$ & 0,27 \\
\hline ratio). . . . . . . . & $5,06 a$ & $4,43 b$ & 4, I I $b$ & $3,84 b$ & \\
\hline
\end{tabular}

\section{Discussion et conclusion}

Les résultats enregistrés entre 6 et Io semaines d'âge ne sont pas très cohérents entre eux ni avec ceux publiés en I976. En effet nous estimions alors que le taux de matières azotées ne devait pas dépasser I3,4 p. cent. L'essai $n^{0}$ I conduit ici à une estimation inférieure, de l'ordre de I3 p. cent, mais pour une croissance médiocre dans les meilleurs lots.

On constate dans l'essai $n^{\circ} 2$ que seul le régime contenant I $_{5}, 3 \mathrm{p}$. cent de matières azotées permet une excellente croissance, comparable à celle de notre étude de I976. Les principales divergences s'estompent lorsque l'on compare les gains de poids aux protéines ingérées de façon à effacer les différences de consommation d'aliment; c'est ce qu'illustre la figure I. Il est alors possible de constater qu'il faut environ $800 \mathrm{~g}$ de protéines à $\mathbf{u n}$ caneton entre les âges de 6 et Io semaines pour exprimer son potentiel maximum de croissance. Cette quantité pouvait être ingérée grâce à un régime renfermant moins de $\mathrm{I} 4,9$ p. cent de matières azotées totales lors de notre étude de 1976 réalisée en hiver dans un local non chauffé (température non enregistrée). Elle ne peut 1'être avec la gamme d'aliment mise en cuvre dans l'essai $n^{\circ}$; celui-ci s'étant déroulé en été avec une température moyenne de $22^{\circ} \mathrm{C}$ entrainant des consommations et des indices faibles. Au contraire dans l'essai no 2 1'utilisation de quatre aliments un peu plus riches et l'abaissement de la température ambiante à $15,5^{\circ} \mathrm{C}$ permet $1^{\prime}$ 'ingestion d'une quantité suffisante de protéines avec les régimes à taux protidique élevé et donc une crois sance correcte.

En conclusion, ces deux essais complètent 1'étude publiée en I976 (LECLERCQ et de CARVII, E). Ils permettent une meilleure définition du besoin et mettent en évidence l'influence du niveau de consommation d'aliment lié en grande partie à la 


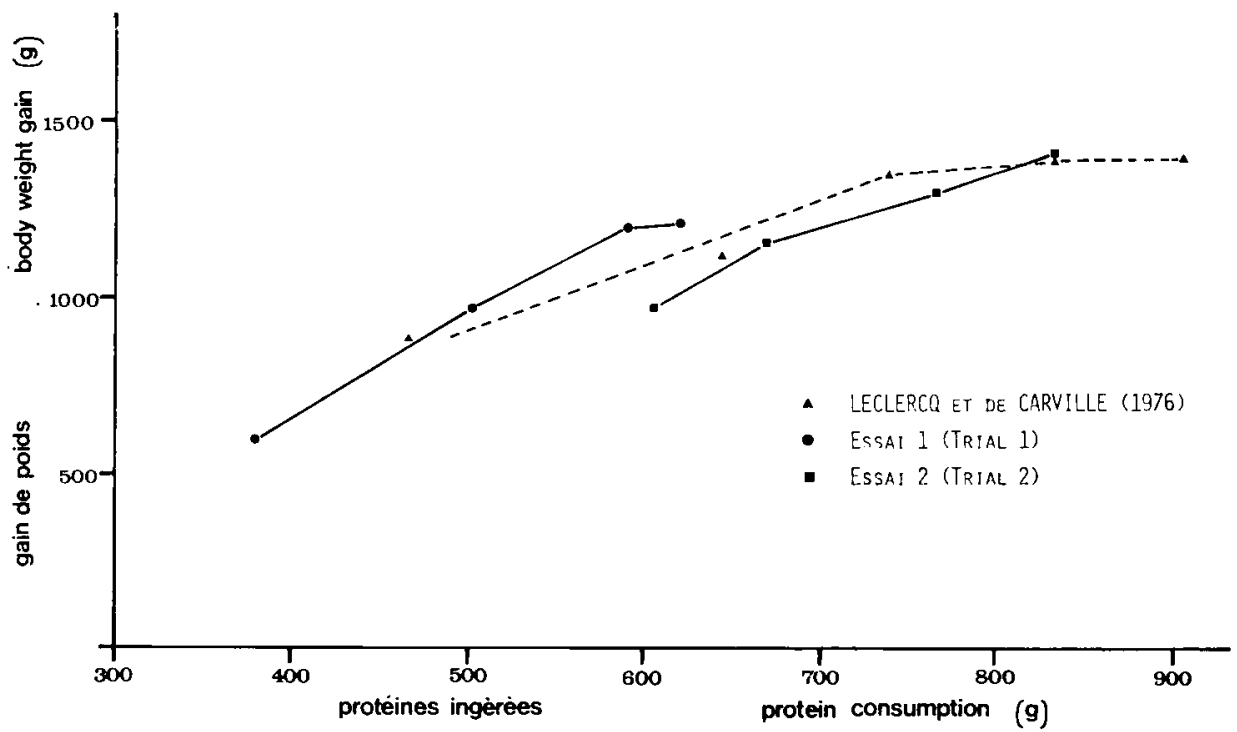

FIG. I. - Gain de poids du caneton de Barbarie entre les áges de 6 et 10 semaines en fonction de la quantité de protéines ingérée

Body weight gain of muscovy ducklings between 6 and 10 weeks of age according to protein consumption

température ambiante. Cette dernière observation conduit à adapter les formules aux conditions d'élevage en adoptant en particulier des caractéristiques différentes selon les saisons. Enfin notre étude est valable pour les mélanges de maïs et de tourteau de soja et demanderait à être complétée pour d'autres sources de protéines. On note cependant grâce à la figure I que la supplémentation par la méthionine (essais $n^{0}$ I et 2 ) des régimes pauvres en protéines ne les rend pas plus efficaces que 1'absence de supplémentation (expérience de r976). Comme nous 1'avons observé précédemment (LECIERCQ et de CARVILLE, I977), il est difficile d'induire une carence très prononcée en acides aminés soufrés chez le caneton avec des régimes à base de maïs et de tourteau de soja.

Accepté pour publication en janvier 1978 .

\section{Summary}

Protein nutrition of Muskovy ducklings: possibilities of reducing the dietary protein level during the finishing period

Two experiments were carried out with the aim of determining the effect of the dietary protein level on growth in male Muskovy ducklings between 6 and Io weeks of age. The estimation of requirements expressed in percent of the diet was affected by the feed intake level, depending to a great extent on the ambient temperature. Expression of the requirements by the total amount of protein necessary for a given period was more satisfactory and allowed to choose different diet characteristics according to rearing conditions and particularly to seasons. The results obtained indicate that the total amount of protein required between 6 and 10 weeks of age represents $800 \mathrm{~g}$. 


\section{Références bibliographiques}

KEULS M., I952. The use of the studentized range in connection with an analysis of variance. Euphytica, 1, I I 2-I 22 .

LECLERCQ B., DE CARviLLE H., I976. L'alimentation azotée du caneton de Barbarie, étude du besoin du caneton mâle entre les âges de 4 et I 2 semaines. Ann. Zootech., 25, I 89-197.

LECLERCQ B., DE CARVILLE H., I977. On the sulphur amino acid requirement of Mruscovy ducklings. Avch. Gefugelk., 41, 270-272.

LECIJRCQ B., DF CARVILLE H., I978. Intérêt du rationnement du caneton mâle de Barbarie entre les âges de 8 et I $z$ semaines. Ann. Zootech., 27, I-7. 